\title{
Sciendo
}

DOI 10.2478/afepuc-2021-0019

(C) 2021 Author(s). This is an open access article licensed under the Creative Commons

Attribution-NonCommercial-NoDerivatives 4.0 International

(https://creativecommons.org/licenses/by-nc-nd/4.0/)

\section{SELECTED GOAL - SCORING CHARACTERISTICS IN THE NATIONAL HOCKEY LEAGUE}

\author{
Silvio Parničan ${ }^{1,2}$, Pavol Peráček ${ }^{1}$, Igor Tóth ${ }^{1}$ \\ ${ }^{1}$ Comenius University in Bratislava, Faculty of Physical Education and Sports, Department of Sports Games, \\ Slovakia \\ ${ }^{2}$ Stjernen Hockey Fredrikstad, Norway
}

Summary: The variables impacting the efficiency of the offensive phase of the game in ice hockey may be determining factor for both the training process and game strategies. The research aimed to acquire and expand the knowledge about selected goal-scoring characteristics in the National Hockey League. A total of 511 even-strength goals were recorded in 129 randomly selected games in a regular-season 2020/2021 by indirect observation. Goals were differentiated by selected variable dimensions: location of the offensive team's puck possession gain before scoring a goal, game situation preceding a goal, and the number of passes of the offensive team preceding a goal. Data were analyzed by performing a oneway ANOVA. Post hoc multiple comparisons were performed using the Tukey HSD test. The significance level of $\mathrm{p} \leq 0.05$ was used. Significant differences were found within all variable dimensions ( $\mathrm{p}=$ 0.00001). In terms of the puck possession gain location, zone 1 (along the boards in the offensive zone) was the zone with the significantly highest mean score $(p=0.00305)$. Offensive zone play was significantly the game situation preceding most of the goals $(\mathrm{p}=0.00000)$. The interval of the passes that preceded most of the recorded goals was the interval of $1-2$ passes $(\mathrm{p}=0.00000)$. Acquired results point out the dominance of particular variables and may help coaches to determine the content of the training process and game strategies. Based on the assumption of the realization of similar research in different environments in terms of the quality and age category, if the analogy would be found between the results of the present study and the results of potential studies, we can state the trends applicable to youth training.

Key words: National Hockey League, ice hockey, game performance, trends, goals. 


\section{Introduction}

Performance analysis has been rapidly increasing in top-class ice hockey over the past years, which has produced growing interest both from spectators and club representatives (Lignell et al. 2020). However, the question of the variables with significant impact on increasing the number of goals requires further research. The rigorous research has been conducted on goal scoring characteristics (GSC) in various team sports stating that particular tactical and contextual variables influence GSC (González-Rodenas et al. 2020; Kubay 2020; Li and Zhao 2021; Mitrotasios et al. 2019; etc). Equally, in ice hockey, it is necessary to determine the variables impacting the efficiency of an offensive phase of the game (OPG). Increased efficiency of OPG results in a higher frequency of goals.

Goal-scoring characteristics should be considered from two standpoints. The primary is from the player's performance (IPP). It is characterized by the player's manifestation during the game (Peráček 2018). IPP simultaneously shows the player's capability to participate in the team's game performance (GPT). GPT is the second important aspect when parsing the GSC. Generally, the GPT and IPP exist in very close connection. GPT is the synthesis of players' performances but in no case their mechanical sum (Peráček 2018).

When we are on the subject of the second standpoint of the GSC - GPT, we mean the mutual activity of the group of players. GPT consists of the IPP of all players (Peráček 2018). From the GSC viewpoint, GPT it is visible in the playing style, which is, according to Fernandez-Navarro et al. (2016, as cited in González-Rodenas et al. 2021) regarded as the general behavior of the team when participating in the tasks of offensive and defensive game. Cooperation between two or more players, coordinated in time and space, is called game combination (Peráček 2003; Tóth 2010). According to Tóth (2010), the mastery of combinations is a precondition for the mastery of the game systems since the game system is realized by combinations (Peráček 2018). The game system is a very foundation of the strategy in both the game's offensive and defensive phase. Výboh (2005) states the following offensive systems: progressive attack, counter-attack (turnover), quick attack, positioning attack, reorganized attack, pressure-based game (offensive zone play). Every game system has its specific features, and its use depends on factors such as the coach's philosophy, typology of the players, level of their cooperation, opponent's style of play, situational context, etc. There is a close relationship between some of the offensive and defensive game systems. Expansion of the knowledge about the most frequent variables that are raising the efficiency of the offensive phase of the game, should be reflected in the higher number of scored goals, and may be the instructive source of information. We assumed that there might be significant differences 
between the variable categories. With regard to specificities of every particular league or competition, if there is an analogy between the results of studies focused on senior and youth age categories, we can name them the trends applicable to youth training.

\section{Methods}

\section{Sample and variables}

The context of the indirect observation was the regular season of the National Hockey League 2020/2021. A total of 511 even-strength goals were recorded in 129 randomly selected games in a regular game time. Every variable was the component of the uninterrupted period from the start of the scoring team's puck possession to the goal's moment. The team's puck possession starts when any one of its players starts controlling the puck. Data were obtained from the available live game broadcasts solely for video analysis and from the official National Hockey League's statistics website (available at http://www.nhl.com/stats/). We designed and used the record sheets for each particular game. Through the option of pause and replay of the goal situations, we could record the data objectively.

\section{Table 1}

Description of the variable categories in terms of the team's game performance

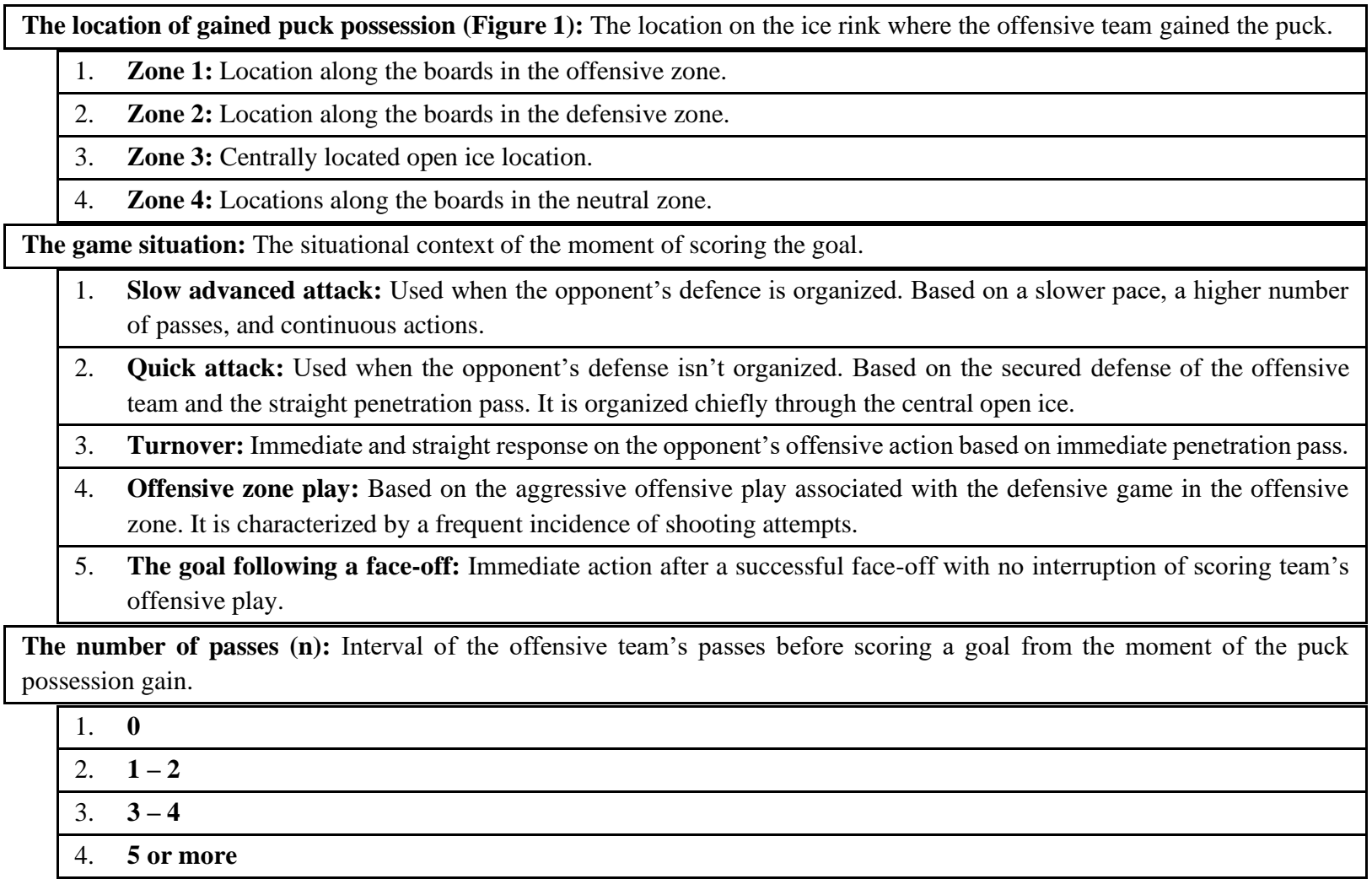


Three variable dimensions in terms of the team's game performance (Table 1) were evaluated. The variables are related to the offensive phase of the game ending with the goal scored.

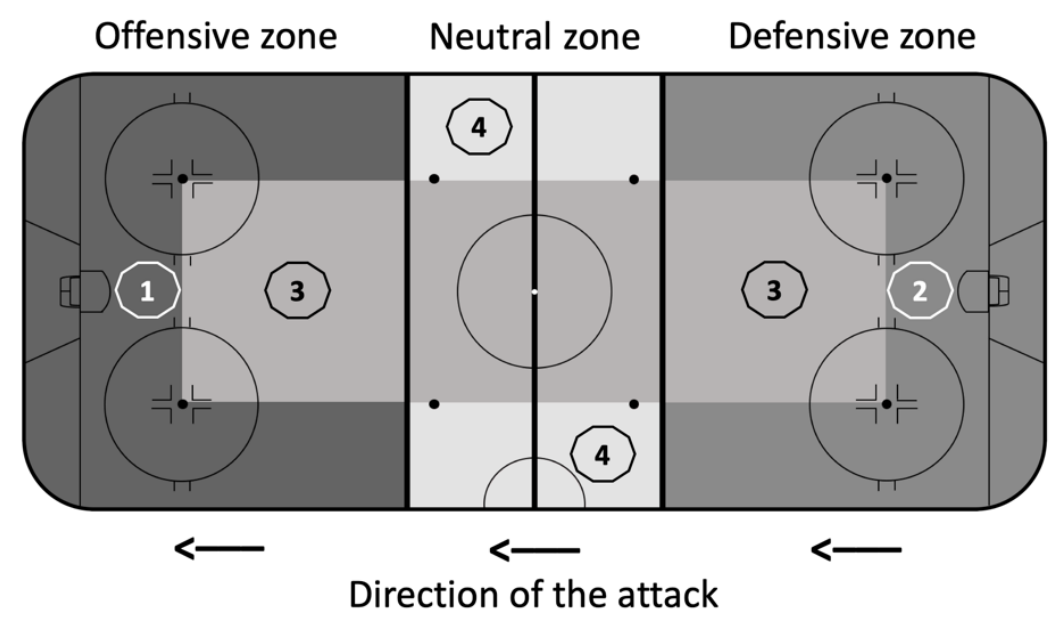

Figure 1

Locations of gaining the puck possession before scoring a goal

\section{Data analysis}

In every goal action considered, the one-way ANOVA was performed to the mutual comparison of the categories of particular variables. Post hoc multiple comparisons were performed using the Tukey HSD test. The significance level of $\mathrm{p} \leq 0.05$ was used.

\section{Results \& Discussion}

As shown in Table 2, there were significant differences found within the goals scored after the gained puck possession in the different locations $[\mathrm{F}(3,512)=47.2798 ; \mathrm{p}=0.00001]$. Post hoc comparisons using the Tukey HSD test indicated the differences between the mean scores of the goals scored after gaining the puck possession in the single locations except between zone $3(\mathrm{M}=0.62, \mathrm{SD}=0.78)$ and zone $4(\mathrm{M}=0.39, \mathrm{SD}=0.64)$. Zone 1 was the location with the highest mean score $(M=1.69, \mathrm{SD}=1.23)$. Individual comparisons of mean scores are shown in Table 3.

Table 2

Analysis of the goals in terms of the locations of gained puck possession

\begin{tabular}{|c|c|c|c|c|c|}
\hline Source of variation & SS & df & MS & F & p \\
\hline Between groups & 137.3081 & 3 & 45.7694 & 47.2798 & 0.00001 \\
\hline Within groups & 495.6434 & 512 & 0.9681 & & \\
\hline Total & 632.9516 & 515 & & & \\
\hline
\end{tabular}


Legend: $S S$ - the sum of squares; $d f$ - degrees of freedom; $M S$ - mean square; $F$ - test statistic; $p$ ANOVA p-value

Table 3

Comparisons between the goals in terms of the locations of gained puck possession - post hoc Tukey HSD test

\begin{tabular}{|l|c|c|c|c|c|c|c|}
\hline \multicolumn{7}{|c|}{ Comparison of locations } \\
\hline $\mathbf{V}_{\mathbf{1}} \mathbf{v s} \mathbf{V}_{\mathbf{2}}$ & $\mathbf{M}_{\mathbf{1}}$ & $\mathbf{S D}_{\mathbf{1}}$ & $\mathbf{M}_{\mathbf{2}}$ & $\mathbf{S D}_{\mathbf{2}}$ & $\mathbf{Q}$ & $\mathbf{p}$ & inference \\
\hline $\mathrm{Z} 1>\mathrm{Z} 2$ & 1.69 & 1.23 & 1.26 & 1.20 & 4.92 & 0.00305 & $* * \mathrm{p}<0.01$ \\
\hline $\mathrm{Z} 1>\mathrm{Z} 3$ & 1.69 & 1.23 & 0.62 & 0.78 & 12.35 & 0.00000 & $* * \mathrm{p}<0.01$ \\
\hline $\mathrm{Z} 1>\mathrm{Z} 4$ & 1.69 & 1.23 & 0.39 & 0.64 & 15.03 & 0.00000 & $* * \mathrm{p}<0.01$ \\
\hline $\mathrm{Z} 2>\mathrm{Z3}$ & 1.26 & 1.20 & 0.62 & 0.78 & 7.43 & 0.00000 & $* * \mathrm{p}<0.01$ \\
\hline $\mathrm{Z} 2>\mathrm{Z} 4$ & 1.26 & 1.20 & 0.39 & 0.64 & 10.11 & 0.00000 & $* * \mathrm{p}<0.01$ \\
\hline $\mathrm{Z} 3>\mathrm{Z} 4$ & 0.62 & 0.62 & 0.39 & 0.64 & 2.69 & 0.22988 & n.s. \\
\hline
\end{tabular}

Legend: $V_{1}$-first variable; $V_{2}-$ second variable; $M_{1}-$ mean score of the first variable; $S D_{1}-$ standard deviation of the first variable; $M_{2}-$ mean score of the second variable; $S D_{2}$-standard deviation of the second variable; Tukey HSD Q statistic; p - Tukey HSD p-value; inference - Tukey HSD inference; $M$-mean score, SD - standard deviation; Z1 - zone 1; Z2 - zone 2; Z3 - zone 3; Z4 - zone 4

Table 4

Analysis of the goals in terms of the game situations preceding the goal

\begin{tabular}{|c|c|c|c|c|c|}
\hline Source of variation & SS & df & MS & F & p \\
\hline Between groups & 169.8822 & 4 & 42.4705 & 53.68807 & 0.00001 \\
\hline Within groups & 506.2791 & 640 & 0.7911 & & \\
\hline Total & 676.1612 & 644 & & & \\
\hline
\end{tabular}

Legend: SS- the sum of squares; df-degrees of freedom; MS- mean square; F- test statistic; $p$ - ANOVA p-value

Table 5

Comparisons between the goals in terms of the game situations preceding the goal-post hoc Tukey HSD test

\begin{tabular}{|c|c|c|c|c|c|c|c|}
\hline \multicolumn{8}{|c|}{ Comparison of the game situations } \\
\hline $\mathrm{V}_{1}$ vs $\mathbf{V}_{2}$ & $\mathbf{M}_{1}$ & SD1 $_{1}$ & $\mathbf{M}_{2}$ & SD $_{2}$ & $\mathbf{Q}$ & $\mathbf{p}$ & inference \\
\hline SAA > QA & 0.74 & 0.88 & 0.26 & 0.49 & 6.04 & 0.00022 & $* * \mathrm{p}<0.01$ \\
\hline $\mathrm{SAA}<\mathrm{TO}$ & 0.74 & 0.88 & 1.00 & 1.03 & 3.37 & 0.12203 & n.s. \\
\hline SAA $<$ OZP & 0.74 & 0.88 & 1.66 & 1.23 & 11.78 & 0.0000 & $* * \mathrm{p}<0.01$ \\
\hline SAA $>$ FFO & 0.74 & 0.88 & 0.30 & 0.61 & 5.54 & 0.00093 & $* * \mathrm{p}<0.01$ \\
\hline $\mathrm{QA}<\mathrm{TO}$ & 0.26 & 0.49 & 1.00 & 1.03 & 9.40 & 0.00000 & $* * \mathrm{p}<0.01$ \\
\hline $\mathrm{QA}<\mathrm{OZP}$ & 0.26 & 0.49 & 1.66 & 1.23 & 17.82 & 0.00000 & $* * \mathrm{p}<0.01$ \\
\hline $\mathrm{QA}<\mathrm{FFO}$ & 0.26 & 0.49 & 0.30 & 0.61 & 0.49 & 0.99680 & n.s. \\
\hline $\mathrm{TO}<\mathrm{OZP}$ & 1.00 & 1.03 & 1.66 & 1.23 & 8.41 & 0.00000 & $* * \mathrm{p}<0.01$ \\
\hline $\mathrm{TO}>\mathrm{FFO}$ & 1.00 & 1.03 & 0.30 & 0.61 & 8.91 & 0.00000 & $* * \mathrm{p}<0.01$ \\
\hline $\mathrm{OZP}>\mathrm{FFO}$ & 1.66 & 1.23 & 0.30 & 0.61 & 17.32 & 0.00000 & $* * \mathrm{p}<0.01$ \\
\hline
\end{tabular}

Legend: $V_{1}$ - first variable; $V_{2}-$ second variable; $M_{1}-$ mean score of the first variable; $S D_{1}-$ standard deviation of the first variable; $M_{2}$ - mean score of the second variable; $S D_{2}$ - standard deviation of the second variable; $Q$ - Tukey HSD Q statistic; p - Tukey HSD p - value; inference - Tukey HSD inference; M - mean score; SD standard deviation 
Significant differences were found between the goals scored differing by the game situation preceding the goal $[\mathrm{F}(4,640)=53.68807 ; \mathrm{p}=0.0001]$. Results are shown in Table 4 . Post hoc multiple comparisons (Table 5) determined the significant differences between the mean scores of variables, excluding the comparison between the goals scored after the slow advanced attack $(M=0.74, S D=0.88)$ and the turnover $(M=1.00, S D=1.03)$. Insignificant difference was equally shown in comparison quick attack $(\mathrm{M}=0.26, \mathrm{SD}=0.49)$ and the goals following the face-off $(\mathrm{M}=0.30, \mathrm{SD}=0.60)$. The game situation with the highest mean score was the offensive zone play $(\mathrm{M}=1.66, \mathrm{SD}=1.23)$.

The ANOVA results of the goals in terms of the number of passes preceding the goal are summarized in Table 6. Significant differences were shown between the categories [F $(3,512)=69.52454 ; p=0.0001]$. Tukey HSD post hoc multiple comparisons found that except of the comparison of the 0 - passes $(M=0.46, S D=0.68)$ and 5 or more passes $(M=0.41, S D$ $=0.62$ ) mean scores, all comparisons found significant differences (Table 7). The $1-2$ passes interval had the highest mean score $(\mathrm{M}=1.98, \mathrm{SD}=1.45)$.

\section{Table 6}

Analysis of the goals in terms of the number of the passes preceding the goal

\begin{tabular}{|c|c|c|c|c|c|}
\hline Source of variation & SS & df & MS & F & p \\
\hline Between groups & 207.5252 & 3 & 69.1751 & 69.52454 & 0.00001 \\
\hline Within groups & 509.4264 & 512 & 0.995 & & \\
\hline Total & 716.9516 & 515 & & & \\
\hline
\end{tabular}

Legend: SS - the sum of squares; df-degrees of freedom; MS - mean square; F - test statistic; $p$ - ANOVA $p$ value

Table 7

Comparisons between the goals in terms of the number of the passes preceding the goal-post hoc Tukey HSD test

\begin{tabular}{|l|c|c|c|c|c|c|c|}
\hline \multicolumn{7}{|c|}{ Comparison of the number of passes } \\
\hline $\mathbf{V}_{\mathbf{1}} \mathbf{v s} \mathbf{V}_{\mathbf{2}}$ & $\mathbf{M}_{\mathbf{1}}$ & $\mathbf{S D}_{\mathbf{1}}$ & $\mathbf{M}_{\mathbf{2}}$ & $\mathbf{S D}_{\mathbf{2}}$ & $\mathbf{Q}$ & $\mathbf{p}$ & inference \\
\hline $0<1-2$ & 0.46 & 0.68 & 1.98 & 1.45 & 17.30 & 0.00000 & $* * \mathrm{p}<0.01$ \\
\hline $0<3-4$ & 0.46 & 0.68 & 1.12 & 1.01 & 7.50 & 0.00000 & $* * \mathrm{p}<0.01$ \\
\hline $0>5$ or more & 0.46 & 0.68 & 0.41 & 0.62 & 0.53 & 0.98209 & n.s. \\
\hline $1-2>3-4$ & 1.98 & 1.45 & 1.12 & 1.01 & 9.80 & 0.00000 & $* * \mathrm{p}<0.01$ \\
\hline $1-2>5$ or more & 1.98 & 1.45 & 0.41 & 0.62 & 17.83 & 0.00000 & $* * \mathrm{p}<0.01$ \\
\hline $3-4>5$ or more & 1.12 & 1.01 & 0.41 & 0.62 & 8.03 & 0.00000 & $* * \mathrm{p}<0.01$ \\
\hline
\end{tabular}

Legend: V1 - first variable; V2 - second variable; M1 - mean score of the first variable; SD1 - standard deviation of the first variable; M2 - mean score of the second variable; SD2 - standard deviation of the second variable Tukey HSD Q statistic; p - Tukey HSD p - value; inference - Tukey HSD inference; M-mean score; SD - standard deviation 
Several related studies focusing on goal-scoring characteristics were conducted in the last two decades (Andrews 2009; Garbe 2013; Elomo and Poikonen 2015; Lignell et al. 2020, etc.). However, there can be differences seen in the systematics, terminology, and data analysis in most cases. As mentioned in the introduction part, characteristics of scored goals or goalscoring patterns are mostly studied in the environment of the different sports games, such as in soccer. In ice hockey, this issue needs to be deeply reviewed. In Garbe's NHL research (2013), $50 \%$ of goals were scored following the puck possession gain in the deeper offensive zone. The mean score of the goals scored after gaining the puck possession in zone $1(\mathrm{M}=1.69, \mathrm{SD}$ $=1.23$ ), representing the location along the boards from the deeper offensive zone, through the grey area up to the blue line, was the highest. The area along the boards is generally the area with the highest incidence of the challenges for the puck. Andrews (2009) stated that most of the NHL goals (58\%) were scored after OZP. Elomo and Poikonen (2015) state the following distribution of even-strength goals in terms of the situational context: OZP - 36\%, rush- $33 \%$, and turnover- $31 \%$. Authors characterize the rush as a controlled attack from a defensive or neutral zone when the opponent has an organized defense. As we can see in this case, the different systematics, methodology, and in particular, the league (Finnish Liiga) must be considered because of the different rink dimensions and level of the competition. In our findings, the goals after gaining the puck in the OZP had the highest mean score $(\mathrm{M}=1.66, \mathrm{SD}$ $=1.23$ ). Garbe (2013) states that most of the goals in the NHL are scored from the counterattacks (36.6\%) with the unorganized defense of the opponent. This proportion of the goals was not significantly different compared to the number of goals after the slow attack with the organized defense of the opponent $(31.11 \%)$ and after the fast break when the opponent is organized (32.29\%). Garbe (2013) has recorded the goals according to the number of passes before a goal: 1 pass- $22.3 \%, 2$ passes- $18.6 \%$, which is a total of $40.9 \%$ of scored goals. Likewise, in our research, most of the goals in terms of the number of passes preceding the goal were scored after $1-2$ passes $(M=1.98, S D=1.45)$. Although the authors used a different statistical approach, we can state that the most dominant variables in most of the referred studies are comparable to our results. Except for Elomo's and Poikonen's study (2015) that was focused on the Finnish Liiga, our data are commensurable with the findings of mentioned studies. The fact is that the NHL differs from the European ice hockey leagues by the level of the game performance and different rink dimensions what causes the different game styles, pace, and tactics. Garbe's findings (2013) are comparable partially due to different systematics of the variables and the different data analysis approach. In addition to the different systematics, 
methodology, and data analysis, the development trends may be another important factor impacting the differences.

\section{Conclusion}

The research aimed to deepen the knowledge about selected characteristics of the National Hockey League goals. Our assumptions about the significant differences between the particular variable categories were confirmed $(\mathrm{p}<0.05)$. Together with the mentioned studies, our research has shown the dominance of specific variables. In terms of the location of gaining the puck possession, zone 1 (along the boards in the offensive zone) was the zone with the significantly highest mean score $(\mathrm{M}=1.69, \mathrm{SD}=1.23 ; \mathrm{p}=0.00305)$. Offensive zone play $[\mathrm{OZP}](\mathrm{M}=1.66, \mathrm{SD}=1.23 ; \mathrm{p}=0.00000)$ was the game situation preceding significantly most of the goals. Interval of the passes that preceded most of the recorded goals, was the interval of $1-2$ passes $(M=1.98, S D=1.45 ; p=0.00000)$. In terms of the game's defensive phase (DPG), acquired results showed the dominance of zone pressing, characterized by an aggressive forechecking to minimize the room for the opponent's offensive play by using double pressure and switching. To maximize the chances of success when using the zone pressing, high activity and efficiency from all five players are necessary. Even the defensemen need to be active when forechecking, most commonly in the pinching activity when the offensive team dumps the puck out by the rim for the winger waiting in the area between the grey zone and the blue line. In this case, the defensive player needs to be supplied on the blue line by the closest player, which is the center in most cases. From the offensive standpoint, the most frequent variable (OZP) points out the association of zone pressing with the aggressive offense play system when the players produce scoring chances immediately after gaining the puck. The most common interval of passes (1-2) preceding the goal confirms this statement.

With regard to different rink dimensions in the NHL, where the rink is smaller than in Europe, we recommend realizing similar research in the elite European senior and youth leagues (e.g., Kontinental Hockey League, Swedish Hockey League, Liiga, etc.). If there is an analogy between the potential results in training, it is necessary to implement the game-based drills and modified games with the forechecking, double pressure, and switching principle in the offensive zone with an effort to quick transition and immediate production of scoring chances. When focusing on the breakout mastering, the emphasis should be put on the drills under pressure with the game's simple transfer to the rink's end zone. 


\section{References}

1. ANDREWS, J., 2009. 2006 - 2007 NHL season goal scoring analysis: Top 15 goal scorers \& top 5 goal scoring teams. Haaga - Helia. University of Applied Sciences.

2. ELOMO, M \& T. POIKONEN, 2015. Analyzing reasons behind the goals in ice-hockey. Haaga-Helia: University of Applied Sciences.

3. FERNANDEZ-NAVARRO, J., et al., 2016. Attacking and defensive styles of play in soccer: analysis of Spanish and English elite teams. In: Journal of Sports Sciences. 34(24), 2195-2204. ISSN 1466-447X

4. GARBE, N., 2013. Goal scoring analysis based on team level in National Hockey League in the season 2006/2007. Haaga - Helia: University of Applied Sciences.

5. GONZÁLEZ-RODENAS, J., et al., 2020. Playing tactics, contextual variables and offensive effectiveness in English Premier League soccer matches. A multilevel analysis. In: Plos One. 15(2), e0226978. ISSN 1932-6203.

6. GONZÁLEZ-RODENAS, J., et al., 2021. The effect of contextual variables on the attacking style of play in professional soccer. In: Journal of Human Sport and Exercise. 16(2), 399-410. ISSN 1988-5202.

7. KUBAY, A., 2020. Analysis of goal scoring patterns in the 2018 FIFA World Cup. In: Journal of Human Kinetics. 71(1), 205-210. ISSSN 1640-5544.

8. LI, C. \& Y. ZHAO, 2021. "The big five"' European football leagues. In: Frontiers in Psychology. 11, 619304. ISSN 2010-9999.

9. LIGNELL, E., et al., 2018. Analysis of goal scoring opportunities in elite male ice hockey in relation to tactical and contextual variables. In: International Journal of Performance Analysis in Sport. 20(6), 1003-1017. ISSN 1474-8185.

10. MITROTASIOS, M., et al., 2019. The creation of goal scoring opportunities in professional soccer. Tactical differences between Spanish La Liga, English Premier League, German Bundesliga and Italian Serie A. In: International Journal of Performance Analysis in Sport. 19(3), 452-465. ISSN1474-81185.

11. PERÁČEK, P., et al., 2003. Teória a didaktika športových hier. Bratislava: Peter Mačura PEEM. ISBN 80-88901-77-4.

12. PERÁČEK, P., 2018. Teória športových hier. Vysokoškolská učebnica pre študentov FTVŠ UK v Bratislave. Bratislava: KO\&KA spol s.r.o. ISBN 978-80-89075-74-4.

13. TÓTH, I. et al., 2010. Tréner l'adového hokeja. Vysokoškolská učebnica pre trénerov špecializácie v l'adovom hokeji. Bratislava: TO-MI Ice Hockey Agency. ISBN 978-80970545-1-9. 
14. VÝBOH, A., et al., 2005. Teória a didaktika l'adového hokeja III: obsahové zameranie tréningového procesu vekových kategórii mladšich žiakov, staršich žiakov, dorastu a juniorov. Bratislava. ISBN 80-969475-1-6. 